\title{
PRODUÇÃO DE AÇUCARES SOLÚVEIS POR PROCESSO NÃO AQUOSO EMPREGANDO SÓLIDOS ÁCIDOS PARA A HIDRÓLISE DE MATERIAIS LIGNOCELULÓSICOS
}

\author{
M.P. LUNARDI ${ }^{1}$ e S.L. JAHN ${ }^{1}$ \\ ${ }^{1}$ Universidade Federal de Santa Maria, Centro de Tecnologia, Departamento de Engenharia \\ Química, Graduação em Engenharia Química \\ E-mail para contato: pmlunardi@gmail.com,sergiojahn@gmail.com
}

\begin{abstract}
RESUMO - Em contrapartida aos processos tradicionais de hidrólise de biomassas, apresenta-se um processo alternativo mecano-catalítico. Para tal, utiliza-se catalisadores sólidos ácidos, obtidos a partir do tratamento de Caulinita e Alumina com ácido sulfúrico, empregando moinho de bolas de alta energia como reator. Rendimentos acima de $20 \%$ são obtidos e podem ser elevados com aquecimento brando do sistema. Oligômeros de glicose são obtidos. Assim, o processo constitui-se numa rota tecnológica capaz de constituir uma rota prévia de única etapa, econômica e de meio não agressivo para o tratamento de biomassas, podendo ser a opção no tratamento prévio para rotas enzimáticas.
\end{abstract}

\section{INTRODUÇÃO}

Abordagem de uma nova rota tecnológica para produção de açúcares a partir das biomassas lignocelulósicas se faz necessária, afim de sustentar a expansão emergente das biorefinarias no Brasil (Rodrigues, 2011). Portanto, a problemática de estudo consiste em: qual outra rota tecnológica se mostra capaz de hidrolisar materiais lignocelulósicos por processo não aquoso empregando sólidos ácidos? Assim, o objetivo é desenvolver um processo alternativo para a hidrólise de biomassas em uma única etapa, utilizando catalisadores, com caráter ácido forte e/ou fraco, empregando processo mecano-catalítico.

\section{REVISÃO TEÓRICA}

A hidrólise hidrotérmica da celulose com ácido clorídrico ou sulfúrico para obtenção de açúcares faz-se presente desde 1945 como traz Aguilar (2002). O inconveniente desses processos centra-se na agressividade do meio utilizado, da baixa seletividade para glicose e formação de subprodutos como o 5-hidroximetilfurfural e furfural, os quais afetam o processo de fermentação para produção de etanol (Mosier, 2002). Ainda, uma elevada demanda energética se mostra necessária para a separação dos açúcares obtidos no meio reacional, visto que nesses processos a catálise é homogênea. Em oposição, surgem as rotas enzimáticas celulolíticas e, apesar de serem altamente seletivas para glicose, mostram baixa atividade na hidrólise de materiais lignocelulósicos conforme Gasparotto (2015). Necessitam, também, de onerosas etapas de tratamento prévio para aumentar o contato das enzimas com a matériaprima. 
Assim, apresenta-se um processo alternativo, que consiste na utilização de catalisadores sólidos com caráter ácido, obtidos a partir do tratamento de Caulinita e Alumina com ácido sulfúrico, substituindo os tradicionais ácidos inorgânicos. Fato que soluciona a dificuldade de separação dos produtos formados, dado que a catálise é heterogênea e ainda, permite a reutilização do catalisador por recalcinação, o que não se faz possível nas rotas comumente difundidas (Fukuoka, 2006). Hick et al. (2010) e Blair et al. (2011) seguem nessa mesma direção e apresentam conversões de celulose microcristalina na ordem de $78 \%$, valendo-se de caulinitas submetidas a tratamentos ácidos e, na hidrólise da palha de milho, atingiram mais de 90\% de solubilização da matéria-prima. Além disso, Barakat (2013) apresenta as vantagens no uso de moinhos de bolas planetário para fornecer energia ao processo de hidrólise de materiais lignocelulósicos. Uma vez que se reduz o número de etapas necessárias para obtenção dos açucares, reduz-se também o consumo energético e o custo total de operação do processo.

\section{METODOLOGIA}

\subsection{Preparação da Biomassa e dos Catalisadores Sólidos}

Preparou-se a biomassa (PF) a ser utilizada como fonte de celulose, constituída de papel de filtração para laboratório, moído em moinho de facas a úmido e, posteriormente, seco em estufa, a $110^{\circ} \mathrm{C}$ por 24 horas e retriturado a seco com auxílio de liquidificador industrial. O caulim empregado como suporte, fornecido pela empresa Inducal - Industrial de Calcário Caçapava - foi inicialmente calcinado a $800^{\circ} \mathrm{C}$ por 4 horas, com a finalidade de transformar a caulinita em metacaulinita. Parcela deste material foi impregnada a seco com ácido sulfúrico em concentrações de $2 \%$, $4 \%$ e $6 \%(\mathrm{~m} / \mathrm{m})$ (amostras denominadas de $\mathrm{CR}_{\mathrm{SA} 1}$, $\mathrm{CR}_{\mathrm{SA} 2}$ e CRA3), procedimento realizado diretamente no moinho de bolas de alta energia. Na sequência, as amostras foram secas a $110{ }^{\circ} \mathrm{C}$ por 24 horas e posteriormente calcinadas a $500{ }^{\circ} \mathrm{C}$ por um período de 4 horas (amostras denominadas de CRsA1-C, CRsA2-C e CRsA3-C).

Caulinita previamente delaminada por tratamento em moinho planetário na presença de uréia e água como sugerido por Tsunematsu e Tateyama (1999), em proporções de 30\% $(\mathrm{m} / \mathrm{m})$, foi submetida a impregnação a seco com 6\% de ácido sulfúrico empregando procedimento descrito acima (amostra denominada de $\mathrm{CR}_{\mathrm{SA} 4-\mathrm{C}}$ ). Também, foram preparados catalisadores onde a metacaulinita foi impregnada com ácido sulfúrico em solução valendo-se de concentrações 0,8 e 4,8 molares. Este procedimento foi realizado no interior de erlenmeyer com auxílio de agitação magnética (120 rpm), empregando uma relação de $10 \mathrm{~mL}$ solução por grama de metacaulinita. Na sequência, o material foi filtrado e seco em estufa a $110^{\circ} \mathrm{C}$ por 24h, gerando as amostras denominadas de $\mathrm{CR}_{\mathrm{CA} 1}$ e $\mathrm{CR}_{\mathrm{CA} 2}$. Alumina foi sintetizada empregando procedimento proposto por Yang et al. (1996). O sólido formado foi calcinado a $550{ }^{\circ} \mathrm{C}$ por um período de 4 hora para formação da fase $\gamma$-alumina e na sequência acidificada a úmido com solução de ácido sulfúrico 0,8 e 4,8 molares, conforme procedimento descrito anteriormente, gerando as amostras denominadas de ALCA1 e ALCA2.

\subsection{Ensaios e Caracterização Catalítica}

Procedeu-se os ensaios catalíticos em moinhos de bolas de alta energia - moinho de bolas planetário Retsch PM 100. Dirigiu-se os ensaios com duração entre 1 e 3 horas, 500 RPM, num copo-reação com volume de $50 \mathrm{~mL}$, com5 esferas de aço com 5 mm de diâmetro. 
A quantidade de papel filtro convertido em produtos foi determinada por processo de solubilização, onde a massa total de produtos foi contatada com $30 \mathrm{~mL}$ de água deionizada por 30 minutos a $50^{\circ} \mathrm{C}$. Na sequência, a fase líquida foi separada da fase sólida com auxílio de centrífuga Eppendorf 5810 a 3000 rpm, sendo a fase sobrenadante encaminhada para análise cromatográfica, visando a quantificação dos produtos formados. O material sólido foi levado à estufa a $110{ }^{\circ} \mathrm{C}$ por 24 horas sendo a massa final quantificada com auxilio de balança analítica. A perda de massa foi determinada por diferença, tomando como base a massa inicial de papel filtro adicionado ao meio reacional.

\subsection{Caracterização Físico-química dos Catalisadores}

As amostras de caulim, metacaulim e alumina, antes e após processo de acidificação, foram caracterizadas por de difração de raios-X, utilizando difratômetro Rigaku, modelo Miniflex 300 empregando radiação $\mathrm{Cu}-\mathrm{K} \alpha(\lambda=1,5418 \AA$ ), fonte de energia com $30 \mathrm{kV}$ e 10 $\mathrm{mA}$, grau de avanço de $0,03^{\circ}$ e tempo de aquisição de $0,5 \mathrm{~s}$. As propriedades texturais das amostras foram determinadas por adsorção e dessorção de $\mathrm{N}_{2}$ a $77 \mathrm{~K}$, ASAP 2020 (Micromeritics), sendo a área de superfície específica $\left(\mathrm{S}_{\mathrm{BET}}\right)$ determinada pelo método Brunauer, Emmett\&Teller (BET). Para as amostras de metacaulim e de alumina fez-se a avalição da presença de grupos hidroxilas e sulfatos por espectroscopia de infravermelho, com auxílio do espectrômetro Prestige, modelo 21210045.

\subsection{Caracterização dos Produtos de Reação}

A caracterização dos açucares foi feita por cromatografia líquida de alta eficiência, com auxílio do cromatógrafo Shimadzu equipado com bomba LC-20AD, degaseificador DGU20A, forno CTO-20A e detector de índice de refração RID-10A. O método de preparo de amostra e análise cromatografica fez-se conforme estabelece Sluiter et al. (2006).

\section{RESULTADOS}

\subsection{Caracterização dos Catalisadores}

Nas análises realizadas por difração de raios X, constatou-se que a alumina apresentou picos característicos da fase $\gamma$ situados em $2 \Theta$ igual a 37,2;39,3;45,7 e 66,8, concordando com a ficha catalográfica JCPDS-ICDD 10-0425. Após os diferentes tratamentos ácidos, constatou-se que o material tratado com solução 4,8 M de ácido sulfúrico apresentou redução na cristalinidade em relação material não tratado, indicando destruição da estrutura cristalina do material. Já o caulim apresentou os picos de difração característicos deste material e após calcinação a $800^{\circ} \mathrm{C}$ a estrutura cristalina foi destruída, indicativo que a caulinita foi transformada em metacaulinita. Da análise de BET constatou-se que a alumina e metacaulinita, utilizados como base para preparação dos diferentes catalisadores, apresentaram superfície específica de $277 \mathrm{~m}^{2} / \mathrm{g}$ e $25 \mathrm{~m}^{2} / \mathrm{g}$ respectivamente.

$\mathrm{Na}$ análise espectroscópica de infravermelho dos catalisadores obtidos a partir da Alumina, constatou-se em todas as amostras a presença de bandas em $3440 \mathrm{~cm}^{-1}$ e em 1650 $\mathrm{cm}^{-1}$, atribuída às vibrações de grupos $\mathrm{OH}$, decorrente da presença de água nas amostras. Para ambas vibrações a intensidade do sinal cai com a elevação da concentração de ácido, mostrando que a estrutura do material foi afetada com o tratamento ácido. A banda próxima a 
$1100 \mathrm{~cm}^{-1}$, presente somente nas amostras tratadas com ácido, é atribuída a presença do grupo sulfato adsorvido nos catalisadores (Contreras, 2006). Já as bandas entorno de $2400 \mathrm{~cm}^{-1}$ indicam a presença de $\mathrm{CO}_{2}$ atmosférico adsorvido nos materiais, conforme Rosário (2012).

\section{Gráfico 1 - Espectros das aluminas.}

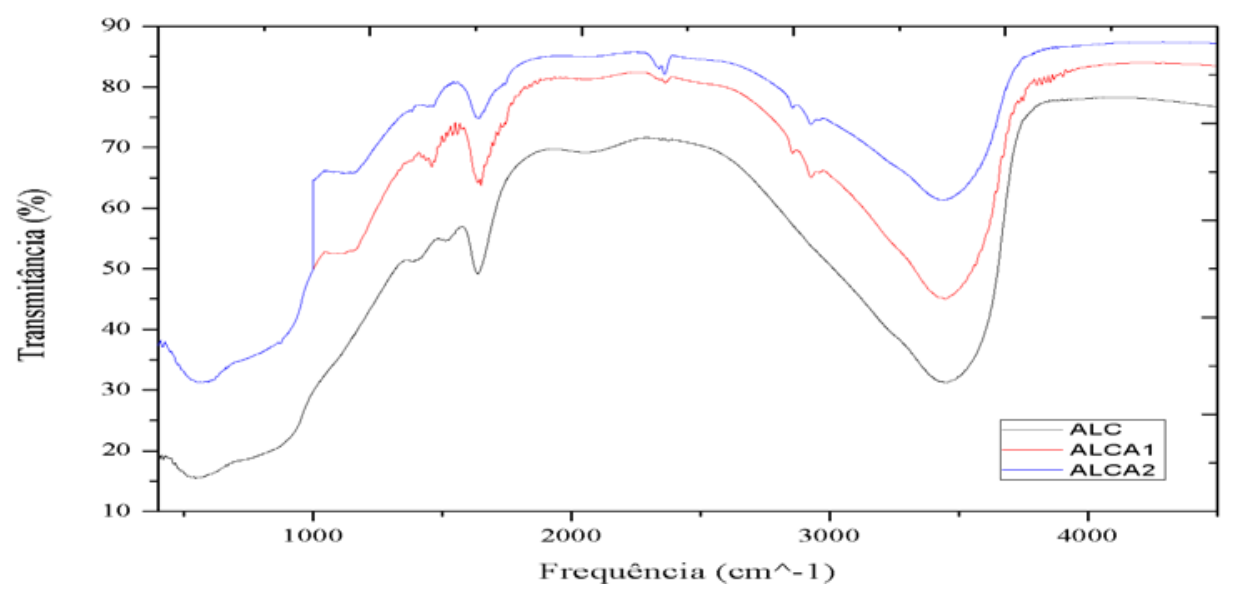

\subsection{Ensaios Catalíticos}

Tabela 1 - Biomassa solubilizada empregando os diferentes catalisadores.

\begin{tabular}{|c|l|c|}
\hline Catalisador & \multicolumn{1}{|c|}{ Descrição } & Biomassa (PF) solubilizada (\%) \\
\hline \hline $\mathrm{AL}_{\mathrm{C}}$ & Alumina calcinada pura & 4,50 \\
\hline $\mathrm{AL}_{\mathrm{CA} 1}$ & Alumina acidificada em solução de $\mathrm{H}_{2} \mathrm{SO}_{4} 0,8 \mathrm{M}$ & 21,17 \\
\hline $\mathrm{AL}_{\mathrm{CA} 2}$ & Alumina acidificada em solução $\mathrm{H}_{2} \mathrm{SO}_{4} 4,8 \mathrm{M}$ & 5,58 \\
\hline $\mathrm{CR}_{\mathrm{C}}$ & Caulim calcinado puro (metacaulinita pura) & 4,95 \\
\hline $\mathrm{CR}_{\mathrm{CA} 1}$ & Metacaulinita acidificada em solução de $\mathrm{H}_{2} \mathrm{SO}_{4} 0,8 \mathrm{M}$ & 4,70 \\
\hline $\mathrm{CR}_{\mathrm{CA} 2}$ & Metacaulinita acidificada em solução de $\mathrm{H}_{2} \mathrm{SO}_{4} 4,8 \mathrm{M}$ & 15,97 \\
\hline $\mathrm{CR}_{\mathrm{SA} 3}$ & Metacaulinita acidificada a seco com $6 \% \mathrm{H}_{2} \mathrm{SO}_{4}$ & 9,78 \\
\hline $\mathrm{CR}_{\mathrm{SA} 1}$ & Metacaulinita seco acidificada a seco com $2 \% \mathrm{H}_{2} \mathrm{SO}_{4}$ & 4,62 \\
\hline $\mathrm{CR}_{\mathrm{SA} 2}$ & Metacaulinita seco acidificada a seco com $4 \% \mathrm{H}_{2} \mathrm{SO}_{4}$ & 9,41 \\
\hline $\mathrm{CR}_{\text {SA3-C }}$ & Metacaulinita seco acidificada a seco com $6 \% \mathrm{H}_{2} \mathrm{SO}_{4}$ e & 8,03 \\
\hline $\mathrm{CR}_{\text {SA4}}$ & Metacaulinita delaminada acidificada a seco $\mathrm{com} 6 \%_{2} \mathrm{H}_{2} \mathrm{SO}_{4}$ & 3,47 \\
\hline $\mathrm{CR}_{\text {SA4-C }}$ & Metacaulinita delaminada acidificada a $6 \% \mathrm{H}_{2} \mathrm{SO}_{4}$ e calcinada & 7,21 \\
\hline
\end{tabular}

A tabela 1 apresenta as proporções de biomassa solubilizada alcançada com os diferentes catalisadores. Os resultados de solubilização da biomassa de papel filtro ficou na faixa de 3,4 \% a 21,2 \%. Dentre os resultados, o melhor desempenho foi obtido empregando a Alumina acidificada com solução 0,8 M de ácido sulfúrico (21,2\%). Já a alumina tratada com solução 4,8 M de ácido apresentou valores inferiores, mostrando que o tratamento afetou o material, como constatado nas análises de infravermelho e raios $\mathrm{X}$. No que diz respeito a alumina pura, sem tratamento ácido, essa também apresentou valores de solubilização baixos. Com relação a utilização de metacaulinita como suporte para ancoragem de ácido sulfúrico, constatou-se que o melhor resultado foi verificado para a amostra obtida com tratamento ácido em solução, empregando 4,8 M de ácido sulfúrico. Já a amostra de metacaulim tratado com 0,8 M de ácido apresentou solubilização na mesma ordem de grandeza do metacaulim sem tratamento ácido, mostrando que tratamento não foi efetivo. 
Também se constatou que o tratamento com ácido sulfúrico denominado a seco realizado sem adição de água - foi menos efetivo que o tratamento realizado a úmido - em solução. Um dos fatores que pode ter afetado de forma positiva a solubilização da biomassa valendo-se da alumina sulfatada como catalisador é o fato desse material apresentar área específica mais de 10 vezes superior ao da metacaulinita. O tempo de reação fora de 2 horas.

\subsection{Caracterização dos Produtos de Reação}

Caracterizou-se os produtos de reação obtidos no ensaio mecano-catalítico empregando o catalisador a base de metacaulinita, acidificada em solução de ácido sulfúrico 4,8 M - CR CA2. Tomando-se como base $100 \mathrm{~g}$ de celulose, pela análise cromatográfica 15,20 $\%$ foi solubilizado, corroborando com os valores encontrados nos ensaios de solubilização. Ainda, observa-se que a conversão é nula para os monômeros de glicose, celobiose, xilose e arabinose, e não nula para monômeros de ácido acético, 5-hidrometilfurfural (5-HMF) e furfural. No que diz respeito conversão em oligômeros, verifica-se valores significativos para glicose. Os valores são apresentados na tabela 2 .

Tabela 1 - Conversão da biomassa em oligômeros de glicose e em outros monômeros.

\begin{tabular}{|c|c|c|c|}
\hline Glicose (\%) & Ácido Acético (\%) & 5-HMF (\%) & Furfural (\%) \\
\hline \hline 25,10 & 5,70 & 12,30 & 56,90 \\
\hline
\end{tabular}

Vê-se que, da glicose presente na fase solúvel, grande parte está na forma oligomérica. Os monômeros de glicose formados foram rapidamente levados a subprodutos (Ogeda, 2010), nesse caso 5-HMF e furfural. Portanto e nessas condições reacionais, a quantidade de subprodutos formados ainda é alta. Outra explicação para tal, centra-se na razão água/celulose alta empregada (3:1), disponibilizando água para a reação ir além da hidrólise da celulose.

\section{CONCLUSÃO}

A obtenção de glicose a partir da hidrólise de materiais lignocelulósicos através de catalisadores sólidos ácidos utilizando-se a rota alternativa proposta mostrou-se possível. Entretanto, os ensaios ainda se encontram em fase preliminar, já que solubilizações mais altas são necessárias - basta-se aquecer brandamente a etapa de reação. Além disso, deve-se procurar aumentar a proporção de glicose formada, proporcionando-se aquecimento do meio, diminuindo-se o tempo de reação e se reduzindo a razão molar água/celulose. Os resultados apontam que o processo se revela capaz de constituir uma rota prévia de única etapa, econômica e de meio não agressivo para o tratamento de biomassas, podendo ser a opção no tratamento prévio para rotas enzimáticas, a fim de quebrar a cristalinidade da celulose.

\section{REFERÊNCIAS}

BLAIR, R. G.; HICK, S. M.; TRUITT, J. H. 2011.

Solid acid catalyzed hydrolysis of cellulosic materials. UCF Patents., n ${ }^{\circ}$ 8,062,428 b2,

HICK, S. M.; GRIEBEL, C.; RESTREPO, D. T.; TRUITT, J. H.; BUKER, E. J.; BYLDA, C.; BLAIR, R. G. 
Mechanocatalysis for biomass-derived chemicals and fuels. G. Chem., 468-474, 2010.

AGUILAR, R..; RAMÍREZ, J. B.; GARROTE, G. VÁZQUEZ, M.;

Kinetic study of the acid hydrolysis of sugar cane bagasse. Food Eng., 309-318, 2002.

BARAKAT, A.; VRIES, H. de.; ROUAU, X.

Dry fractionation process as an important step in current and future lignocellulose biorefineries: A review. Bio Tech., 134, 362-373, 2013.

CONTRERAS, C.; SUGITA, S; RAMOS, E. 2006.

Preparation of sodium aluminate from basic aluminum sulfate. Azojomo., v. 10.2240,

ROSÁRIO, D. C. C.

Estudo da influência dos íons Mg2+ e Zr4+ na transição de fase amorfo-gama da alumina. Politécnica SP., ed. revisada, p. 91, 2012.

FUKUOKA, A.; DHEPE, P. P.

Catalytic conversion of cellulose into sugar alcohols. Angew Chem Int., ed. 45, 51615163,2 006.

GASSPAROTTO, J. M.; WERLE, L.B.; FOLETTO, L.B.; KUHN, E.L.; JAHN, S.L.; MAZUTTI, M.A.

Production of cellulolytic enzymes and application of crude enzymatic extract for saccharification of lignocellulosic biomass. App Biochem and biotech., 175, 560-572, 2015.

OGEGA, L. T.; PETRI, F. S.

Biomass enzymatic hydrolysis. Quim. Nova., v. 33, p. 1549-1558, 2010.

MOSIER, N. S.; LADISCH, C. M.; LADISCH, M. R.

Characterization of acid catalytic domains for cellulose hydrolysis and glucose degradetion. Biotech. Bioeng., v. 79, p. 610-618, 2002.

RODRIGUES, J. A. R.

Do engenho à biorrefinaria. A usina de açúcar como empreendimento industrial para a geração de produtos bioquímicos e biocombustíveis. Quim. Nova., v. 34, p. 1242-1254, 2011.

SLUITER, A.; HAMES, B.; RUIZ, R.; SCARLATA, C.; SLUITER, J.; TEMPLETON, D.

Determination of sugars, byproducts, and degradation products in liquid fraction process samples. National Renewable Energy Laboratory., NREL/TP-510-42623, 2008.

TSUNEMATSU, K.; TATEYAMA, H.

Delamination of urea-kaolinite complex by using intercalation procedures. Ceram. Soc., v. 82, p.89-91, 1999.

YANG, T.; CHANG, T.; YEH, C.

Acidities of sulfate species formed on a superacid of sulfated alumina. J. of Molec. Catalysis., v. 115, p. 339-346. 